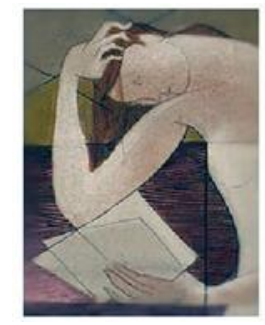

\title{
O nacional e o global em Antonio Candido: uma leitura de Formação da literatura brasileira e "Literatura e subdesenvolvimento" 1
}

\author{
National and global in Antonio Candido: an analysis of Formação da Literatura \\ Brasileira and "Literatura e subdesenvolvimento"
}

\author{
Marcelo Lotufo $^{2}$
}

\begin{abstract}
Resumo: Este ensaio avalia como Antonio Candido pensa, em dois momentos distintos de sua obra, a saber, em Formação da Literatura Brasileira (1959) e "Literatura e Subdesenvolvimento" (1969), a inserção da literatura brasileira dentro de um sistema internacional de trocas literárias. Aberto para os debates sobre economia e política, Candido reformula em "Literatura e Subdesenvolvimento" o modelo de Formação para incorporar os debates sobre desenvolvimento e dependência feitos a partir dos anos 1960, buscando maior autonomia para a literatura nacional dentro de um sistema internacional de trocas literárias, sem deixar de ser crítico ao atraso socioeconômico do Brasil. Espera-se com isso também analisar como o lugar de enunciação do modelo de Candido, quando comparado ao de Pascale Casanova, uma das maiores referências para os estudos em Literatura Mundo, demonstra uma maior preocupação com a autonomia da literatura LatinoAmericana.
\end{abstract}

Palavras-chaves: Antonio Candido; literatura mundo; teoria da dependência; Formação da literatura brasileira; "Literatura e subdesenvolvimento"

Abstract: This essay investigates how Antonio Candido develops, in two moments of his work (in Formação da Literatura Brasileira (1959) and "Literatura e subdesenvolvimento" (1969)) the relationship between Brazilian literature and an international system of literary exchanges. Open for debates on economy and politics, Candido reworks the literary model of Formação incorporating the 1960's development and dependency theories to his thinking. He seeks, with this new approach, to reconsider the autonomy of national literatures in an international literary system, while also criticize the socioeconomic reality of Brazil and the disparities of such system. Furthermore, reading Candido's developments side by side with that of Pascale Casanova's, this essay argues that the attention paid by Candido the national autonomy springs from his own locus of enunciation situated at the margins of such international literary system.

Keywords: Antonio Candido; world literature; dependency theory; Formação da literatura brasileira; "Literatura e subdesenvolvimento"

\footnotetext{
${ }^{1}$ Uma versão preliminar deste ensaio foi apresentada no simpósio "Antonio Candido: balanço crítico" organizado por Alfredo Cesar de Melo no Instituto de Estudos da Linguagem da Unicamp em outubro de 2019. Agradeço a todos os participantes do evento pelas críticas e sugestões.

2 Mestre e doutor em Literatura Comparada pela universidade de Brown, nos EUA. No momento desenvolve pesquisa como pós doutor no Instituto de Estudos da Linguagem da Unicamp com financiamento Fapesp
} 

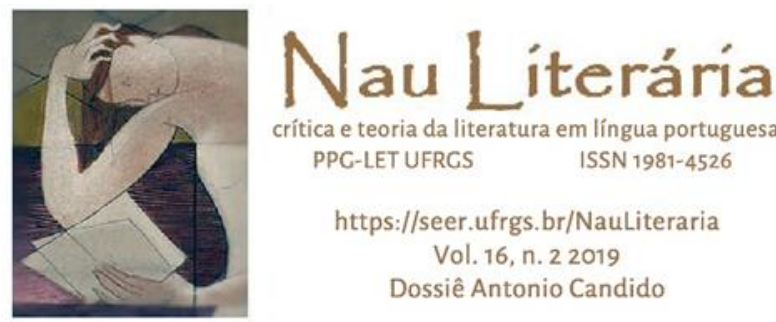

\section{Introdução}

O ressurgimento dos debates sobre literatura mundial, literatura mundo, World Literature e Weltliteratur, no final da década de 1990 e início dos anos 2000, não recebeu, no Brasil, a mesma atenção que em outros países. Se nos mundos anglófono e hispânico os trabalhos de Pascale Casanova, David Damrosh e Franco Moretti geraram respostas, questionamentos e debates acalorados, no Brasil a recepção destes autores, e a polêmica que os acompanhou em outros países, foi mais tímida. ${ }^{3}$ Curiosamente, entretanto, duas das leituras mais importantes deste ressurgimento, os trabalhos de Casanova e Moretti, dialogam, respectivamente, com os críticos brasileiros Antonio Candido e Roberto Schwarz.

O tema principal destes debates, a circulação de livros e formas literárias além das fronteiras nacionais onde foram produzidas, assim como as linhas de força que moldam esta circulação, não são uma novidade para o leitor brasileiro. A prevalência de metáforas geográficas na nossa crítica, do "entre-" ao "fora de" lugar, deixa clara a importância, nos debates críticos brasileiros, de situar o Brasil dentro de um sistema internacional de trocas literárias. Desde a independência do país, ou, mais precisamente, da publicação da primeira história literária sobre o Brasil, o lugar da literatura nacional dentro de um sistema literário mais amplo, ligado aos processos de colonização, persiste. Isto é, o debate sobre a existência ou não de uma literatura brasileira, e da sua relação com a literatura portuguesa, que seguiu a publicação da história da literatura brasileira de Ferdinand Denis em 1826 era, também, um debate sobre os termos da articulação da literatura brasileira com o sistema literário ocidental. A prevalência do tema "circulação" nos debates acerca da literatura brasileira possivelmente fez com que as proposições de Moretti, Casanova e outros não fossem vistas como grandes

\footnotetext{
${ }^{3} \mathrm{~A}$ força com que o tema ressurge no mundo anglófono pode ser facilmente percebida pela enorme quantidade de ensaios com as palavras "world literature" publicada nos mais diversos periódicos anglófonos após os anos 2000. Já no mundo hispânico, ressalto aqui a publicação da coletânea América Latina en la 'literatura mundial (2006), organizada por Inacio Sanchez Prado, assim como os livro de Héctor Hoyos e Mariano Siskind, respectivamente, Beyond Bolaño: The Global Latin American Novel e Cosmopolitan Desires: Global Modernity and World Literature in Latin America. No caso do Brasil e dos estudos brasileiros, o debate mais influente que tocou o tema da literatura mundial foi sobre a recepção de Machado de Assis no exterior, feito a partir do ensaio "Leituras em competição", de Roberto Schwarz. Ressalto, também, o ensaio do crítico Luís Bueno, "Literatura mundial e tradição interna", publicado em 2010.
} 

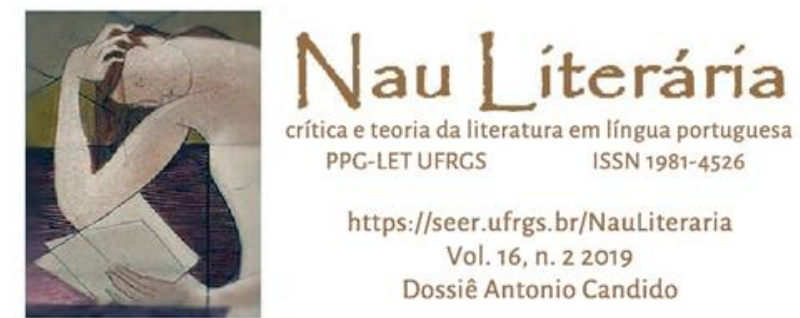

novidades no país, recebendo atenção menor do que em outros contextos. ${ }^{4}$ Ainda assim, a presença dos escritores brasileiros nestes modelos e, principalmente, como as questões de circulação de livros e formas literárias em um sistema internacional moldam no Brasil os debates sobre a literatura nacional há mais de um século, merecem atenção.

Por uma questão de extensão, e por já ter tratado do caso de Roberto Schwarz em outro lugar, ${ }^{5}$ focarei aqui somente no trabalho de Antonio Candido. Proponho, então, investigarmos como Candido incorpora ao seu conhecido modelo para pensar o surgimento de uma literatura nacional um modelo para se pensar também as trocas literárias internacionais, assim como as divergências do seu modelo quando comparado com o de Casanova. Na extensa obra de Antonio Candido, dois momentos parecem centrais para entendermos como o crítico pensa a inserção da literatura brasileira em um sistema literário internacional: Formação da Literatura Brasileira: momentos decisivos, publicado em 1959, mas escrito entre 1945 e 1955, e "Literatura e Subdesenvolvimento", publicado em 1969. Estes textos representam momentos chaves para a articulação que Candido faz entre a literatura brasileira e a literatura europeia, assim como mostram a importância para Candido em responder ao seu próprio momento histórico, participando das discussões políticas e sociais sendo feitas sobre o Brasil no momento em que o crítico escreve. A importância desta preocupação com o Brasil, com o lugar periférico a partir de onde o crítico escreve e pensa, o levam a tratar com maior atenção a questão da autonomia da literatura nacional quando comparado a articulações propostas por CASANOVA (1999).

Em seu ensaio "Uma palavra instável", Candido fala dos diferentes sentidos que a palavra "nacionalismo" adquiriu no século XX, indo de um "ufanismo patrioteiro" a uma "defesa do patrimônio econômico" contra o imperialismo da guerra fria, ou, no âmbito cultural, da "fascinação provinciana" por fontes europeias à "consciência da nossa diferença" (1995, pp. 304-5). De forma semelhante, a maneira como o crítico articulou a relação da

\footnotetext{
${ }^{4}$ Ver, neste sentido, BUENO (2010, p. 127).

${ }^{5}$ LOTUFO, Marcelo. "O papel da teoria da dependência em Roberto Schwarz", Hispania, v. 97, n. 4, dezembro 2014, pp. 589-599.
} 

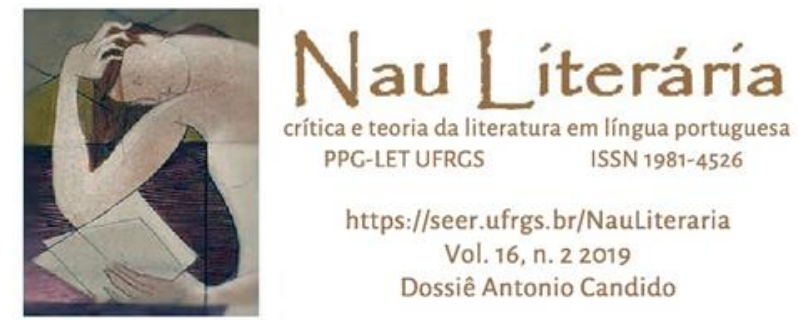

nossa literatura com suas matrizes europeias e o sistema de trocas literário internacional também tomou diferentes formas ao longo dos anos. Se após os estudos pós- e de-coloniais é fácil apontar que Candido e sua geração não avistavam além da tradição europeia, a abertura para o contemporâneo que o seu modelo propõe é um convite para repensarmos o próprio modelo do crítico a partir de outros desafios e debates, reescrevendo-o para responder às nossas preocupações contemporâneas.

\section{Formação da Literatura Brasileira e o devir ocidental}

Em Formação da Literatura Brasileira, a questão da brasilidade - ou do que diferenciaria a nossa literatura da portuguesa e, consequentemente, da europeia - é o problema central que preocupa o crítico e baliza a maneira como ele pensa a relação entre Brasil e Europa. É a partir desta busca que nossa literatura começaria a se configurar como uma tradição específica, diferente da portuguesa. Ao desenvolver o que nos seria próprio, uma tradição local se consolidaria, permitindo que autores buscassem influência nas gerações locais que os precederam. A origem desta literatura, entretanto, se daria no seio da literatura colonial, uma vez que a nossa cultura letrada seria um desenvolvimento da portuguesa e teria, $a b$ ovo, que lidar com a influência de tradições já estabelecidas. Em outras palavras, a literatura brasileira, para ser reconhecida como tal, precisaria negociar a sua participação em um sistema internacional de trocas literárias. Estudar literatura brasileira, neste sentido, como afirma o próprio crítico em outro lugar, seria sempre estudar literatura comparada (CANDIDO, 1993, p. 211).

O modelo proposto por Candido para se pensar a relação do Brasil com as tradições europeias, bastante conhecido, repetido e debatido, é o da árvore. O de uma literatura que se forma como um galho de outra mais antiga e já consolidada. O nó do nosso debate crítico, a tensão entre o local e o global, baliza a maneira como Candido pensa a própria literatura nacional e, por isso, o seu modelo para a formação da literatura brasileira é, também, um modelo para pensar a relação desta com a literatura ocidental. Se, por um lado, para se constituir como um tradição, a literatura nacional precisa buscar algo que a diferencie - um 

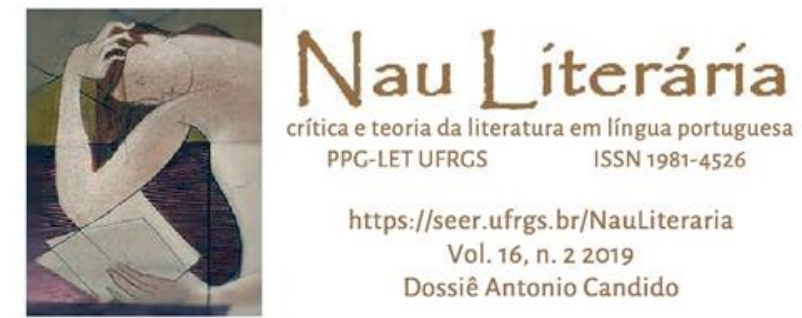

elemento local e particular - ela também está presa à literatura europeia, pois seria fruto do projeto colonial e de expansão do velho continente. Como aponta Luís Bueno, para Candido a literatura brasileira equilibra-se "entre o desejo de atualização com o não nacional e um desejo de expressão do nacional" (2010, p.107). Para estudá-la, então, seria preciso um modelo que não se prendesse somente a um destes aspectos, mas que articulasse o nacional e o internacional; o local e o global etc.

Se recuperarmos o que, para Candido, é o passo formativo da literatura brasileira, a saber, a passagem do Arcadismo para o Romantismo, fica clara a importância da entrada do Brasil em um sistema internacional de trocas literárias para a maneira como o crítico pensa a formação da tradição nacional. Para Candido, a entrada neste sistema literário precederia e autorizaria a própria busca pela nacionalidade. O binômio "arcadismo-romantismo", também descrito por Candido como "neoclassicismo-romantismo", representa um embate entre uma tendência universalista e uma nativista ou localista. A importância do Arcadismo neste esquema, visto da perspectiva da consolidação de uma tradição, não estava na busca da originalidade local, o que marcaria o romantismo, mas sim na integração do Brasil em um sistema internacional de trocas literárias já estabelecido. "O movimento arcádico significou, no Brasil," segundo Candido, "a incorporação da atividade intelectual aos padrões europeus tradicionais, ou seja, a um sistema expressivo segundo o qual se havia forjado a literatura do Ocidente" (2007, p. 327). Nesta leitura, os brasileiros, junto do desejo de ter uma literatura própria, também demonstravam um desejo de pertencer a um sistema literário específico, a saber o europeu/ocidental.

Só depois de estabelecido este pertencimento, pela repetição das formas consagradas, o país estaria "apto" a buscar a sua própria identidade, criando, a partir da literatura portuguesa, um galho próprio. É esta certeza de pertencer ao sistema ocidental que, segundo Candido, dava ao Romantismo a liberdade de pesquisa e busca por novos temas e formas, sem que precisasse abrir mão da tradição europeia e, não sem problemas, do legado colonial dos quais se consideravam herdeiros. Quando Ferdinand Denis, por exemplo, sugere que se busque a literatura perdida dos indígenas brasileiros, ele não sugere uma real mudança de 

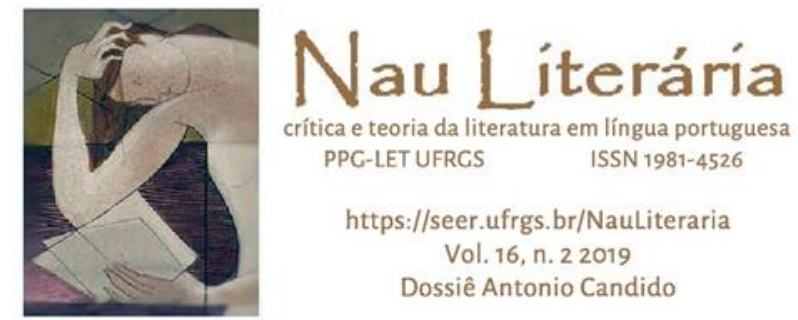

paradigma para a literatura que se formaria no país, uma virada antropológica, mas afirma a certeza de que novas formas e temas poderiam ser aproveitadas pela literatura ocidental, assim como o romantismo europeu aproveitara lendas nórdicas e histórias folclóricas alemãs e francesas. Nas palavras hoje bastante problemáticas do viajante e historiador francês, estas histórias e tradições autóctones seriam uma contribuição importante dos indígenas para "a raça dos vencedores”, isto é, para a própria tradição europeia (1826, p. 524). A inserção do Brasil neste sistema de trocas, assim como o lugar secundário que ocupava, já estavam em pauta para Denis e, como percebe Candido, continuariam definindo a nossa literatura durante grande parte do século XIX.

Isto é, o Romantismo se definiria pela busca da diferenciação da literatura brasileira em relação à europeia, pela busca e desenvolvimento do que seria próprio na literatura brasileira e, consequentemente, daquilo que poderia ser a contribuição do país para a literatura ocidental. Em outras palavras, o nacional não significava a recusa do internacional, mas uma nova articulação entre os dois. A brasilidade estaria nos temas e conteúdos que o Brasil oferecia à tradição, enquanto o universal, neste caso, estaria resguardado pela maneira como este conteúdo seria trabalhado, pensado sempre dentro da tradição ocidental estabelecida. "Tendo-se originado de uma convergência de fatores locais e sugestões externas, [o romantismo] é [no fundo] ao mesmo tempo nacional e universal" (CANDIDO, 2007, p. 332). Daí percebe-se a importância, para os primeiros românticos brasileiros, mas também para a leitura que Antonio Candido faz deles, da tríade Germaine de Stael, Alexander von Humboldt e François Auguste Chateaubriand, que estabeleceram em seus próprios trabalhos as bases para a busca da representação de uma nova realidade americana. Dentro da própria tradição europeia estavam as bases do nacionalismo romântico. As pesquisas e invenções dos românticos brasileiros, assim, estavam previamente autorizadas por autores europeus e eram parte do processo de entrada da literatura brasileira neste sistema literário. $\mathrm{O}$ fruto nunca cai longe da árvore.

O equilíbrio entre os dois polos, entre o local e o global, entre o nacional e o europeu, entretanto, não é sempre estável em Formação e tangencia, em alguns momentos, uma 

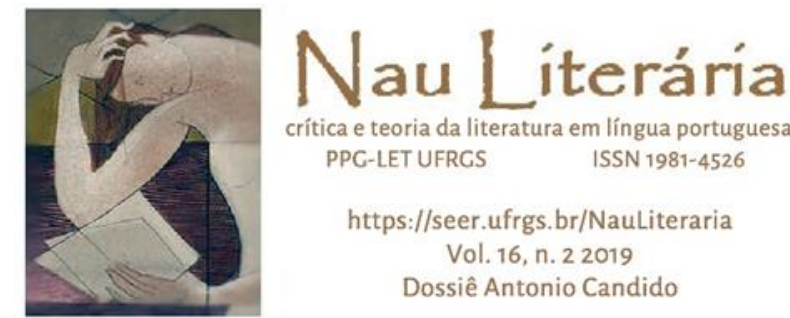

teleologia do desenvolvimento literário. Descrita como uma literatura jovem, seria natural então que envelhecêssemos, nos aproximando das literaturas europeias. Surgem como sinônimos do binômio local e global, ou nacional e europeu, outros binômios mais judicativos, que indicam o desejo do próprio crítico em ver a literatura alcançar um lugar específico. Assim como para Pascale Casanova, também parece haver para o Cândido de Formação um "Meridiano de Greenwich literário" localizado entre o primeiro e o décimo nono arrondissement parisiense e que demarcaria o presente da modernidade literária. Dependendo da distância da literatura brasileira em relação à europeia, os adjetivos "forte e fraco", "jovem e maduro", "pobre e rico", são utilizados no livro. Há nestes binômios, logicamente, uma preocupação com as condições materiais para que a literatura floresça, condições as quais deveríamos almejar: melhores escolas, universidades, bibliotecas, imprensa livre etc. Mas há também uma naturalização de um percurso, incompleto no livro, mas que desembocaria nas próprias literaturas europeias; uma naturalização do processo colonial que, como Candido aponta em "Literatura de dois gumes", escrito algumas décadas depois, não era somente uma questão de desenvolvimento cultural, mas parte de um processo mais amplo de dominação ideológica ${ }^{6}$. A instauração de uma cultura europeia no Brasil se deu a partir do deslocamento de outras culturas que já existiam aqui e não foi um processo natural, mas uma disputa violenta, um enfrentamento tanto cultural como militar. Em Formação, entretanto, a violência deste processo não recebe atenção e o global, ou europeu, se torna quase que naturalmente o ponto de chegada do próprio do local.

Como aponta Abel Barros Baptista,

se adotarmos a dicotomia recorrente na historiografia literária brasileira, incluindo na versão candidiana, é forçoso reconhecer que, na definição de literatura, o 'universal' ou 'geral', ou 'cosmopolita') predomina necessariamente sobre o 'local' mesmo nos momentos de forte particularização (2003 p.57).

Baptista continua afirmando que a literatura brasileira - principalmente na leitura candidiana - buscaria momentos de vindicação do local contra o universal, um apontamento que reforça

\footnotetext{
${ }^{6}$ Agradeço ao professor Alfredo Cesar de Melo por apontar esta relação.
} 

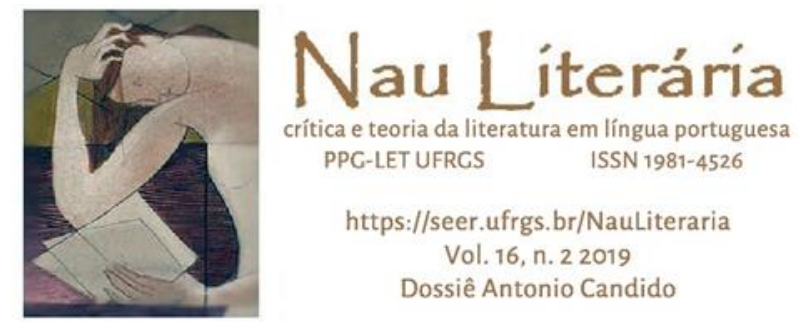

a importância do binômio para a crítica brasileira. Interessa em nossa leitura, entretanto, apontar como a predominância do global sobre o local faz Formação repetir o desejo de mundo dos próprios autores que estuda, um desejo decimonônico que pautou as discussões literárias brasileiras desde Ferdinand Denis. ${ }^{7} \mathrm{O}$ paradigma de Candido, na construção de uma narrativa histórica para a literatura brasileira, segue a perspectiva romântica que tenta resguardar o caráter "ocidental" da literatura brasileira enquanto busca investigar o que haveria de particular na mesma. E se a historiografia literária brasileira descreve este desejo e a maneira que a literatura brasileira encontrou para entrar neste sistema, ao aceitá-lo como inevitável, favorece-se assim a continuidade do desequilíbrio que ela mesmo reconhece.

O resultado prático desta "preferência em última instância pelo global" em Formação pode ser percebido na leitura que Candido faz, neste livro, do romance brasileiro. A leitura de Macedo como um pequeno realista, ou a compreensão de que o tamanho fluminense das personagens de Alencar eram um resultado das condições precárias do Brasil (condições de país jovem, atrasado etc.) deixam claro que a régua usada por Candido para medir o êxito destes autores em Formação é o realismo europeu de Balzac. Em certa medida, em vez de ler tais autores nos seus próprios termos, Candido procura em Formação o que lhes falta para serem outros; para atingir o nível supostamente universal da literatura europeia. O local, inferior em qualidade, precisaria abrir espaço para o global florescer o que, no modelo proposto, se daria em Machado de Assis, ponto de chegada do livro em questão. A revalorização das tensões entre local e global como algo produtivo para o romance brasileiro, e não mais como algo a ser superado, seria revista pelo crítico em 1970, no ensaio "Dialética da Malandragem", sobre Manuel Antonio de Almeida. É também na década de 1970, com os desenvolvimentos dos debates sobre subdesenvolvimento e dependência na sociologia e na política, que a relação entre local e global será reavaliada na obra de Antonio Candido, como veremos a seguir.

\section{3 "Literatura e subdesenvolvimento" e a busca por autonomia}

\footnotetext{
7 Ver, neste sentido, LIMA, 1992.
} 

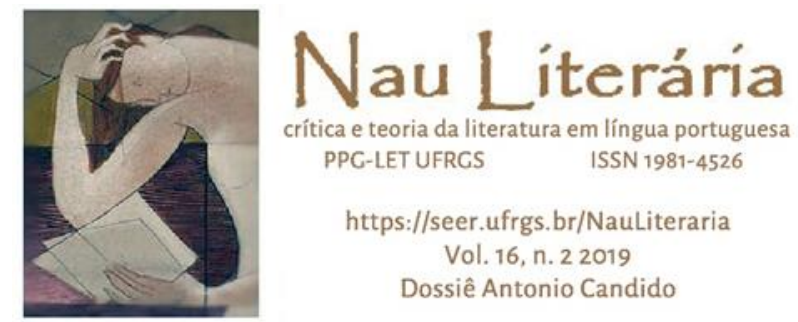

Em "Literatura e subdesenvolvimento", Antonio Candido retoma, mais de uma década depois de Formação, o desafio de pensar um modelo para articular a relação da literatura brasileira com sua matriz europeia. O texto retorna ao tema central de Formação da Literatura Brasileira, isto é, a busca por entender e definir a especificidade da literatura nacional e da sua relação com a cultura europeia, mas agora fora da chave nacionalista imposta pelo romantismo; uma chave que, como exposto na seção anterior, se confunde em momentos com a própria narração historiográfica proposta por Candido em Formação.

Escrito originalmente como parte de uma coletânea de ensaios sobre o continente latino-americano, organizada pela Unesco em 1969, "Literatura e subdesenvolvimento", como o título indica, olha para os debates socioeconômicos sobre desenvolvimento econômico para entender a produção cultural da América Latina, deixando para trás de uma vez por todas a ênfase romântica no determinismo da natureza e da geografia para pensar o continente. ${ }^{8} \mathrm{O}$ tema, assim como o caráter continental da abordagem, eram parte do projeto do livro e estavam em pauta nos anos 1960 em grande medida como resultado das articulações feitas através da CEPAL, órgão da próprio Unesco que buscava pensar de forma crítica e interdisciplinar o estado do continente e o crescimento econômico das ditaduras militares que proliferavam na América Latina.

Conforme a década avançava, com altas taxas de crescimento, mas sem uma mudança considerável no nível de desigualdade social, tornava-se claro o limite do modelo etapista e teleológico usado até o momento para pensar a região. A América Latina não repetia a história da Europa, estando em um momento anterior de desenvolvimento, mas traçava um caminho com desafios próprios, oriundos de sua história de ex-colônia e da sua integração tardia no capitalismo mundial, como fornecedora de matéria-prima e mercados. Estava claro que não bastavam paciência e crescimento para se atingir um nível socioeconômico europeu nas Américas. Era necessário repensar os modelos que haviam pautado as leituras e políticas públicas do continente até aquele momento, levando em conta agora a história do processo

\footnotetext{
${ }^{8}$ Para o contexto de publicação do ensaio de Candido, ver GOMES, 1988.
} 

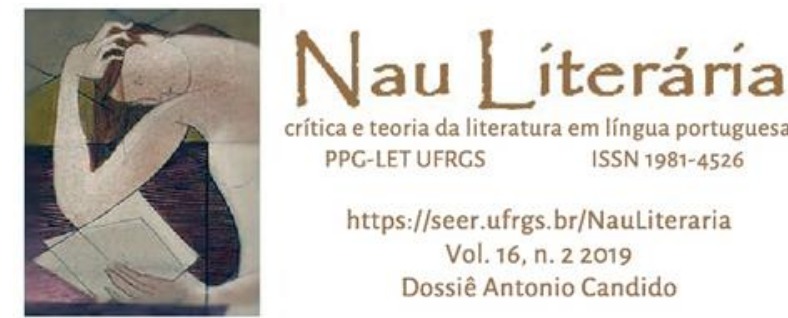

colonial, assim como as desigualdades inerentes do sistema capitalista internacional no qual estes estados haviam surgido. O termo subdesenvolvimento, na década de 1960, procurava começar a descrever e entender estes desafios.

A mudança na percepção do continente, como aponta Grínor Rojo, é acompanhada por Antonio Candido em seu trabalho, que seria

exemplar nesses aspectos, pois cobre os três momentos que articulam a sequência cronológica da postulação desenvolvimentista, desde o seu primeiro aparecimento como teoria do desenvolvimento até sua esquerdização ocorrida com os dependentistas radicais dos anos 1960" (2018, p. 162).

Se retomarmos os termos usados por Candido em Formação e compararmos com os usados em "Literatura e subdesenvolvimento", a importância desta mudança de paradigma para a cultura também fica clara. Isto é, Candido abandona a ideia de um país "jovem" ou "atrasado" que precisaria de tempo para crescer e alcançar um desenvolvimento econômico, mas também cultural, europeu. A ideia de crescimento por etapas, popular nos anos 1950, é deixada de lado e Candido se adequa aos debates sobre subdesenvolvimento feitos nos anos 1960. Ou seja, o crítico passa a enfatizar que os desafios da América Latina para desenvolver uma cultura letrada não eram explicáveis somente pela juventude do país, mas estavam ligados à história de colonialismo que marcara o continente e ao próprio sistema capitalista e o lugar marginal que estes países ocupavam nele.

Em "Literatura e subdesenvolvimento", "atrasado" e "avançado" passam a ser entendidos como realidades contemporâneas e deixam de ser etapas em um mesmo processo, tornando-se condições estruturais do próprio sistema. Para a literatura nacional isto significa que ela precisa ser entendida também nos seus próprios termos e não mais como um momento de passagem para se chegar ao nível da grande literatura ocidental, para o local chegar ao global. Os problemas estruturais do país e as dificuldades que estes geravam para o aparecimento de um sistema literário completo, com obras, escritores e leitores, ganham um novo significado. São resultados de anos de colonialismo. Na cultura, como aponta Candido, estas desigualdades não eram exteriores às obras produzidas, pois atuavam "na consciência do escritor e na própria natureza da sua produção" (CANDIDO, 2006, p. 176). A condição 

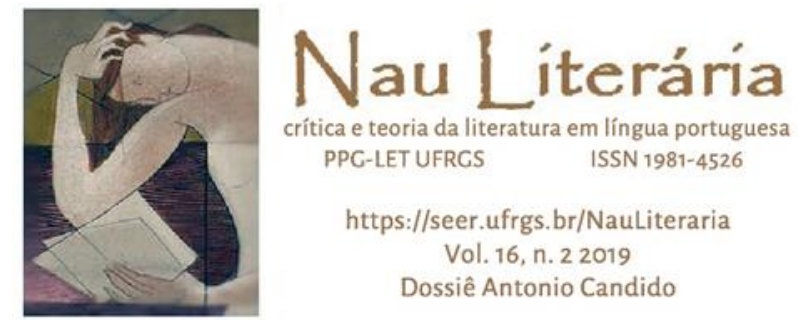

do continente tem resultados na literatura produzida, nos problemas com os quais esta trabalha. Ela não é mais vista como uma versão simplificada e imatura da literatura europeia, mas como uma literatura que lida com desafios próprios. O desejo de se tornar europeu não é parte de uma teleologia natural da cultura letrada, como poderia parecer em momentos de Formação, mas o resultado da história do próprio sistema, que levou escritores brasileiros a produzirem uma literatura que respondesse tanto à sua realidade nacional, como às expectativas das suas ex-metrópoles, muitas vezes não conseguindo responder de forma adequada a nenhum dos dois impulsos.

É importante ressaltar que a diferença na articulação entre local e global em "Literatura e subdesenvolvimento" em relação ao proposto por Candido em Formação não está na reconsideração da história desta relação, que continua seguindo o modelo da árvore, tendo sua origem na literatura europeia. Em "Literatura e subdesenvolvimento", Candido repete a conhecida formulação da literatura brasileira como um galho novo, mas agora expandindo a noção para todo o continente:

as nossas literaturas latino-americanas, como também as da América do Norte, são basicamente galhos das metropolitanas. E se afastarmos os melindres do orgulho nacional, veremos que, apesar da autonomia que foram adquirindo em relação a estas, ainda são em parte reflexas (2006, p. 182).

A mudança de paradigma está, como já apontado, na relação entre estas partes, que passam a ser vistas como integrais de um mesmo sistema e não como etapas a serem superadas. A preocupação com a autonomia da literatura nacional também surge com mais força nos anos sessenta.

Para explicar a relação entre literatura nacional e sistema internacional, Candido introduz a palavra "dependente", que torna-se uma importante mediadora entre o local e o global tanto na literatura, como na economia. A cultura europeia, ele diz, estaria "sociologicamente vinculada à nossa dependência, desde a própria colonização e do transplante por vezes brutalmente forçado das culturas" (2006 p.182). A naturalidade deste processo presente em Formação é deixada de lado, sendo vista agora como um processo "brutalmente forçado". O termo dependente permite que a história de colonialismo e as 

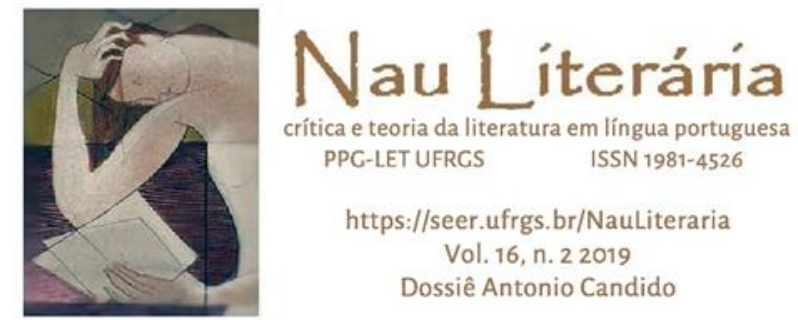

desigualdades do sistema capitalista internacional sejam inseridas na relação entre local e global, entre literatura nacional e internacional que, dentro do sistema de trocas, e na luta por hegemonia que o acompanha, teriam forças diferentes. Isto é, uma literatura advinda do colonialismo, em uma sociedade formada sobre trabalho escravo, mesmo forjada dentro do horizonte da cultura ocidental, não poderia simplesmente tornar-se europeia. $\mathrm{O}$ que, entretanto, não significa que - do ponto de vista literário - ela não possa desenvolver-se de forma original a partir destas formas impostas pelo contexto colonial.

O termo "dependência" também distancia a construção de Candido da ideia popular no período de "desenvolvimento do subdesenvolvimento," elaborada pelo alemão Andre Gunder Frank e que, do ponto de vista da cultura, ainda mais do que da economia, significava um engessamento da América Latina em uma posição subalterna. Frank via o continente preso em uma condição subdesenvolvida da qual não conseguiria sair a não ser pela via revolucionária. As possibilidades para inovação eram nulas, uma vez que o continente só seria capaz de reproduzir o seu próprio subdesenvolvimento. Tal noção, entretanto, fora combatida pelos "dependentistas" que viam maior dinamismo no continente, principalmente na relação entre a elite local e o capital internacional. Ao tomar este vocabulário, Candido busca articular o global e o local na literatura de uma forma produtiva, preservando a autonomia e a capacidade de inovação do segundo termo, sem deixar de assinalar os desafios socioeconômicos e históricos do continente. Apesar de todo os problemas advindos do subdesenvolvimento (analfabetismo, instituições precárias, falta de continuidade interna etc.), o continente poderia produzir literatura de alta qualidade que fosse além da cópia de seus modelos europeus ou da reprodução do que já fizera. A relação entre o local e o global, na literatura, não precisava ser sempre conflituosa. Encontradas formas que respondessem à sua realidade específica, aos seus próprios desafios, a literatura nacional poderia seguir um caminho próprio, desenvolvendo seus próprios gêneros e formas literárias, encontrando seus próprios temas e soluções.

A mudança de paradigma, a passagem do etapismo à dependência, pode parecer pequena e distante do debate literário, mas é o que permite Antonio Candido reconsiderar as 

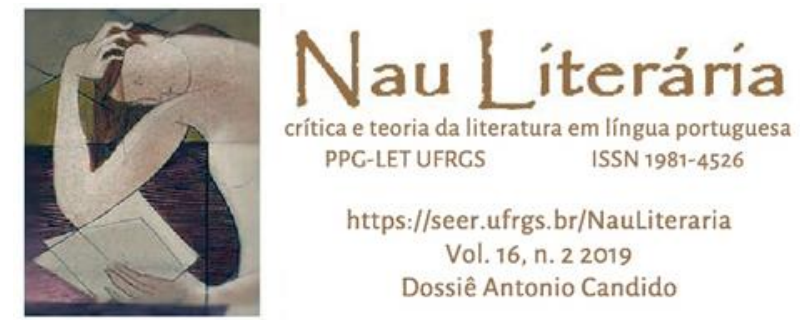

possibilidades da literatura nacional dentro do sistema global, tornando o seu modelo mais dinâmico. É através desta mudança que ele mostra como a literatura brasileira não precisaria se resumir à busca de conteúdos nacionais, mas poderia também desenvolver novas combinações a partir da tradição que recebera via colonização. Não era mais preciso definir o romance nacional, por exemplo, como uma versão menor ou local das mesmas formas europeias, como era o caso com o "pequeno realismo" ou o "tamanho fluminense" em Formação. É possível buscar, na literatura brasileira, um novo realismo que responda a outras questões, não postas pela realidade de Balzac e Flaubert, como veremos a seguir, mas sim pela de Alencar e Macedo. Não é preciso, também, esperar para cumprir etapas, pois a dependência cultural, quando consegue situar seus próprios problemas e dar-lhes uma forma literária adequada, é capaz de produzir literatura inventiva e original mesmo em um sistema precário. A releitura que Candido faz no período de Manuel Antonio de Almeida é sintomática. Se em Formação o autor era um excêntrico no cenário brasileiro, criador de um romance picaresco superficial que não encontrava formas sociais complexas o suficiente para torná-lo um grande escritor, em "Dialética da malandragem", publicado um ano depois de "Literatura e subdesenvolvimento," Manuel Antonio de Almeida passa a ser visto como aquele que melhor deu conta, formalmente, da incerteza da vida da pequena burguesia carioca, presa entre o favor e a aversão ao trabalho típicas de uma sociedade escravista como a do Brasil oitocentista. Almeida, isto é, deixa de ser uma etapa em direção a literatura europeia e passa a ser visto nos seus próprios termos.

Em outras palavras, a próprio realidade subdesenvolvida do país passa a ser vista como um desafio para a literatura nacional, que precisa encontrar sua própria maneira de representar esta realidade. A mesma lógica usada na leitura de Memórias de um sargento de milícias, é usada em "Literatura e subdesenvolvimento" para se ler Guimarães Rosa. O encontro da realidade brasileira com as formas do romance psicológico e urbano é visto na origem do que Candido denomina "super-regionalismo", um novo gênero criado por Rosa, uma espécie de regionalismo-universal que não existiria na Europa. Este movimento de recriar formas literárias a partir da realidade e suas contradições particulares na América 

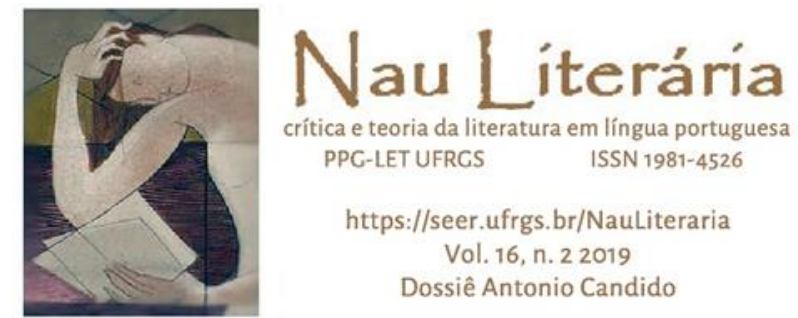

Latina, Candido chama em de "processo de fecundação criadora da dependência" (2006, p. 184). Isto é, se na economia o subdesenvolvimento do país era necessariamente negativo, os resultados deste na cultura podiam surpreender, ainda que não se devesse perder o olhar crítico para a realidade material da região. A literatura não precisava estar presa em um momento de estagnação - sempre local e aquém do global - por causa da condição socioeconômica do país, nem presa a um percurso já delineado pela literatura europeia, mas poderia encontrar novas maneiras de falar sobre o local, contribuindo com suas próprias inovações, e não somente com matéria prima como sugerira Ferdinand Denis, para o sistema literário internacional.

O nó de Formação entre local e global continua central em "Literatura e subdesenvolvimento", mas a nova preocupação de Candido com o debate sobre desenvolvimento e subdesenvolvimento o move em uma nova direção, afastando-o do teleologismo do primeiro livro, e incorporando nas suas formulações para um sistema de trocas literárias internacional uma maior autonomia para a literatura brasileira.

\section{Conclusão: Candido, Casanova e a abertura para o presente}

Ao cotejar a maneira como Antonio Candido articula o local e o global, o nacional e o internacional, o brasileiro e o europeu, em Formação da Literatura brasileira e em "Literatura e subdesenvolvimento," podemos tirar algumas conclusões. Primeiro, não é por acaso que Antonio Candido tem sido retomado com interesse pelos debates acerca de uma literatura mundial, no sentido desenvolvido principalmente por Pascale Casanova, mas também - via Roberto Schwarz - por Franco Moretti e Fredric Jameson. Há em seu trabalho uma tentativa de pensar a relação da literatura brasileira com suas matrizes europeias, recuperando seus sentidos no tempo e no espaço. Isto é, há um interesse de pensar a literatura nacional como parte de um sistema maior de trocas literárias, respeitando a autonomia das literaturas nacionais, sem deixar de ser crítico às desigualdades do sistema onde elas se inserem. 

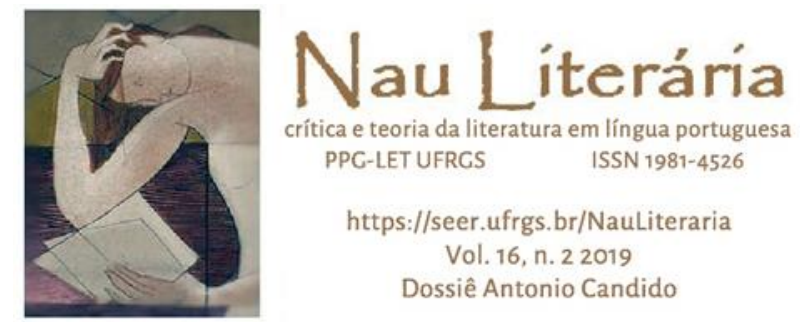

Segundo, a preocupação de Antonio Candido com a autonomia das literaturas não centrais é uma importante contribuição do crítico para o debate acerca de um sistema internacional, ou mundial, de trocas literárias. Se a crítica mais recorrente ao modelo de Casanova está na maneira como ela articula a relação das literaturas periféricas com a Francesa, imaginando ser Paris o termômetro da modernidade literária de todo o sistema literário mundial e, portanto, o ponto de chegada desejado por todas as demais literaturas, Candido aponta que esta relação precisa ser vista de uma forma mais crítica, levando em consideração a história de colonialismo e dependência que forjou o próprio sistema literário em questão. Por fim, Candido também mostra que independentemente das desigualdades deste sistema e dos desafios socioeconômicos de cada região, as literaturas produzidas na América Latina podem ser originais e criativas. Se o presente está sempre alhures, como pensa Casanova, a única forma de realmente alcançá-lo está em transformar-se no outro, o que torna a teorização de um sistema literário internacional em outra forma de colonialismo, negando autonomia a todos aqueles que não estão nos países centrais. A abertura de Candido para incorporar os debates sobre desenvolvimento e dependência em seu modelo apontam para uma tentativa de não congelar a periferia em uma etapa que leva ao centro, mas a abertura de vê-la como dinâmica e produtiva.

A imaginação de Paris como o presente da modernidade revela o caráter teleológico que o modelo de Casanova continua a apresentar, algo que, como mostramos, Candido reformula na passagem de Formação da Literatura Brasileira para "Literatura e subdesenvolvimento." Vale notar, ainda, que se Candido deixa para trás o vocabulário etapista, que apontava a Europa como o futuro da América Latina, Casanova continua apegada a uma noção de progresso histórico que não se mostra aberta para desenvolvimentos fora do centro. Suas formulações pensam a Europa não necessariamente como contemporânea à América, mas como o seu futuro. A Modernidade literária que todos buscariam, afinal, estaria ali. Esta certeza, entretanto, leva a análises que, quando lidas com mais cuidado, não se sustentam. O caso de Mário de Andrade, estudado em seu livro, é emblemático. Para a crítica francesa, Mário seria o inventor do português moderno e ocuparia 

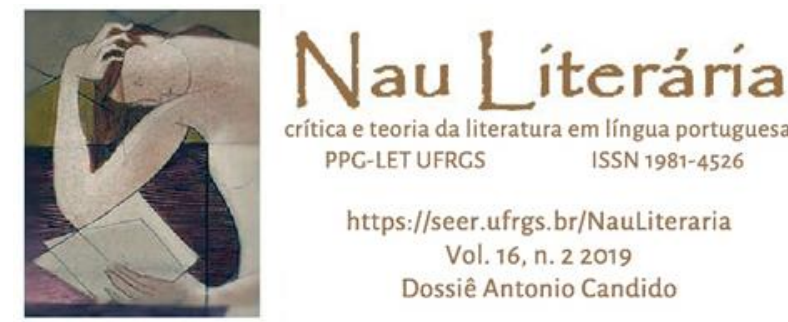

a mesma posição que Du Bellay teria ocupado para a língua francesa no século XVI. "Podemos dizer que Mário de Andrade está na posição exata de Du Bellay uma vez que Du Bellay reivindicava o fim na dependência do francês em relação ao latim" (p. 400). A peculiaridade histórica de cada processo, assim como toda a história de colonização das Américas, se perde na comparação da crítica francesa, a qual serve somente para reforçar o lugar privilegiado - de exemplo a ser seguido - que a literatura francesa ocupa no seu modelo. Não há uma abertura real a outra literatura, que está presa em um caminho já traçado e a complexidade de Mário de Andrade é reduzida à de Du Bellay. Ao inserir a ideia de "dependência" em seu modelo, entretanto, Candido mostra que os desenvolvimentos literários fora do centro, mesmo quando lembram aqueles de países europeus, tem outros significados e precisam portanto ser vistos também dentro de seus contextos específicos.

Candido se aproxima de Casanova, entretanto, ao mostrar que o horizonte da literatura brasileira estudada por ele, assim como de seu próprio modelo, é a literatura ocidental. A imagem da árvore, usada por Candido tanto em Formação da literatura brasileira como em "Literatura e subdesenvolvimento", mostra que, para o crítico, a literatura brasileira como a conhecemos não poderia existir além do próprio legado colonial. Do ponto de vista histórico isto é um fato a ser encarado. O processo de ocidentalização da cultura brasileira, entretanto, mesmo hegemônico na cultura letrada, não deve ser visto como inevitável, pois em uma sociedade formada sobre trabalho escravo e genocídio indígena ele está sempre em disputa. Incorporar outras tradições não ocidentais ao debate de um sistema literário internacional, mas também na formação da própria literatura nacional, parece ser o novo desafio que as teorias sistêmicas precisam enfrentar. Nesse sentido, a abertura do trabalho de Antonio Candido para novos debates como o da dependência e a disposição do crítico para rever suas posições e incorporar novas perspectivas ao seu modelo são uma lição que deve continuar pautando nossas tentativas de pensar tanto a literatura nacional, como o sistema literário internacional em que ela se insere. Esta abertura para o presente ao se pensar literatura é uma importante contribuição brasileira para os debates acerca de um sistema literário mundial e que precisa ser resgatada. 

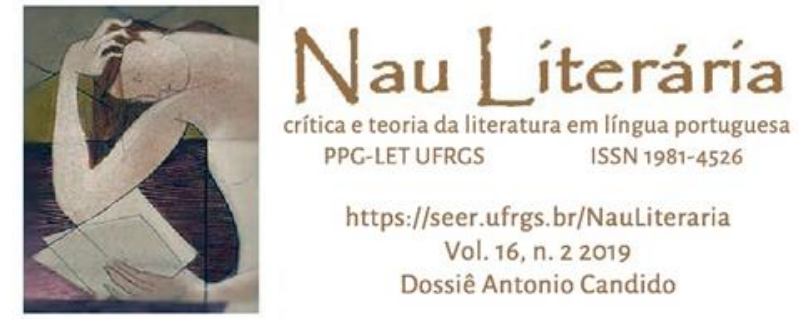

\section{Referências}

BAPTISTA, Abel Barros. A formação do nome: duas interrogações sobre Machado de Assis. Campinas: Editora da Unicamp, 2003.

BUENO, Luís. "Literatura mundial e tradição interna", em Cerrados - Revista do Programa de Pós-Graduação em Literatura, Brasília, n. 28, p. 114-132, 2010.

CANDIDO, Antonio. Formação da Literatura Brasileira: momentos decisivos. Rio de Janeiro: Ouro Sobre Azul, 2007.

. "Literatura e subdesenvolvimento", em A educação pela noite. Rio de Janeiro: Ouro Sobre Azul, 2006.

__. "Literatura de dois gumes", em A educação pela noite. Rio de Janeiro: Ouro Sobre Azul, 2006.

_. "Uma palavra instável", em Vários escritos. São Paulo: Duas Cidades, 1995.

_. "Literatura Comparada", em Recortes. São Paulo: Cia das Letras, 1993.

CASANOVA, Pascale. La republique mondiale des lettres. Paris: Seuil, 1999.

DENIS, Ferdinand. Resumé de l'histoire littéraire du Portugal, suivi du resumé de l'histoire litteráire du Brésil. Paris: Lecointe et Durey.1826.

FRANK, Andre Gunder. The development of underdevelopment. Nova York: Monthly REview Press, 1966.

GOMES, Renato Cordeiro. "Para além das fronteiras: literatura e subdesenvolvimento, de Antonio Candido", em Cadernos de Linguística e Teoria Literária, Belo Horizonte, n. 910, pp. 117-127, 1988.

LIMA, Costa. "Concepção de história literária na Formação", em Dentro do texto, dentro da vida. Org. Maria Angelo D'Incao e Eloísa Scarabôtolo. São Paulo: Cia das Letras, 1992.

ROJO, Grínor. "Antonio Candido em diálogo com a teoria do desenvolvimento, o desenvolvimentismo e a teoria da dependência", em Antonio Candido 100 anos. São Paulo: Editora 34, 2018. 